\title{
Performance of lot-fed Bos indicus steers exposed to aspects of a feedlot environment before lot-feeding
}

\author{
J. C. Petherick ${ }^{\mathrm{A}, \mathrm{B}}$, R. G. Holroyd ${ }^{\mathrm{A}, \mathrm{B}}$ and A. J. Swain ${ }^{\mathrm{A}, \mathrm{C}}$ \\ ${ }^{\mathrm{A}} \mathrm{CRC}$ Cattle and Beef Industry (Meat Quality) \\ ${ }^{B}$ Department of Primary Industries, Agency for Food and Fibre Sciences, \\ PO Box 6014, CQMC, Rockhampton, Qld 4702, Australia. \\ ${ }^{\mathrm{C}}$ Department of Primary Industries, Agency for Food and Fibre Sciences, \\ Animal Research Institute, Locked Bag 4, Moorooka, Qld 4105, Australia.
}

\begin{abstract}
Fifty Bos indicus steers, 2-3 years old, were exposed to aspects of a feedlot environment on their home property for 9 days (pre-exposed). A further 50 steers were placed in a holding paddock for the 9 days (naïve). Twenty steers in each group became 'focal animals' for periodic blood sampling and behaviour observations. The cattle were transported for $15 \mathrm{~h}(950 \mathrm{~km})$ to an experimental feedlot where they were lot-fed for 100 days, with productivity (liveweight, body condition and feed intakes) and flight speeds recorded at intervals. A subjective fear of humans test was conducted on the pre-exposed group during the 9 days in the yards on the home property and carcass traits were measured on all cattle.

Both groups lost substantial weight on the property and during transportation. On the property, the pre-exposed steers lost about $12 \%$ of their original liveweight and the naïve about $9 \%$. Transit losses were a further 5 and $4 \%$ of pre-transport liveweights, respectively. The steers did not reach their initial liveweights until day 41 of feedlotting.

The pre-exposure treatment did not affect final liveweight, but feed intakes were lower for the pre-exposed animals than the naïve ones during the first 16 days of feedlotting, and the pre-exposed steers had superior average daily gains and feed conversion efficiencies. These effects were probably due to a combination of compensation and improved feed digestibility, as a result of the pre-exposed animals being under-fed on the property, but receiving concentrated grain supplement. There was no effect of focal status on productivity.

Flight speed and the subjective fear of humans test were significantly correlated. Neither treatment nor focal status affected flight speeds, but flight speeds decreased in the latter part of feedlotting, were highly correlated between days and negatively correlated with average daily gain and intakes.
\end{abstract}

\section{Introduction}

Cattle that are finished in feedlots experience dramatic changes in their environment in a short period of time. Breeding and rearing properties are generally 'extensive', with the animals grazing large paddocks at low stocking rates and often drinking from natural water sources such as creeks or dams. Frequently, there is minimal handling of the cattle, so the animals have little experience of humans. In contrast, feedlots are 'intensive' with cattle stocked in relatively small areas, at high stocking rates and with frequent exposure to, if not direct handling from, humans. Furthermore, feedlot cattle not only drink from troughs, but also obtain feed from troughs. The feed is very different to the pasture that animals experience on breeding and rearing properties. Thus, much of the feedlot environment is novel and novelty is a very potent stressor because it induces a state of fear (Boissy 1995; Grandin 1997).

In addition to stress resulting from fear, there is also stress associated with the numerous aspects of the transportation process, such as intermittent access to food and water, mustering and handling, close confinement and crowding, disruption of social bonds, possible exposure to climatic extremes, physical exhaustion and trauma (Tarrant and Grandin 1993). On arrival at the feedlot, cattle are subjected to the induction process that involves procedures such as handling, restraint, vaccination, tagging and weighing, which will add to the stress the cattle experience (Fell et al. 1999).

Cattle tend to be in feedlots for relatively short periods of time (usually 70-100 days). Thus, for good production efficiency, it is imperative that cattle rapidly recover from the numerous stressors, and become accustomed to the feedlot environment and the associated management practices. Furthermore, there are obvious welfare implications for cattle that do not rapidly adapt to the feedlot environment; some animals can become sick, while others may not eat or drink. Morbidity levels can be high during the first few weeks of feedlotting (Hutcheson and Cole 1986; Dunn et al. 1998).

One way of reducing the stress experienced by feedlot cattle is to reduce fear. This could be achieved by exposing 
cattle to some of the aspects of the environment that they will encounter, in order to reduce novelty (Gonyou 1993; Grandin 1997). Obviously, this exposure must be a neutral or positive experience for the cattle so as to avoid inducing fear (Grandin 1997). Cattle that are familiar with close confinement and proximity to other cattle, eating and drinking from troughs and exposure to humans and vehicles should become accustomed to the feedlot environment more rapidly than naïve animals. This may be manifested through improved productivity. Furthermore, cattle that are fearful are likely to cope less well with stressors that invoke fear than less fearful cattle (Petherick et al. 2002).

This experiment investigated whether providing cattle with some experience of aspects of a feedlot environment, such as confinement in yards, trough-feeding with concentrated grain supplement, and exposure to humans and vehicles, before feedlot entry would reduce fearfulness and enhance productivity.

\section{Materials and methods}

\section{Location and climatic conditions}

The cattle were bred on a commercial property $\left(19^{\circ} 40^{\prime} \mathrm{S}, 145^{\circ} 45^{\prime} \mathrm{E}\right)$ situated in the subcoastal black spear grass region (Weston et al. 1981) of North Queensland, Australia. The climate is dry tropical, characterised by a distinct hot, wet period (the summer wet season) and a warm, dry period (winter), which is followed by a hot, dry period (the dry season).

The cattle were transported to Brigalow Research Station $\left(24^{\circ} 50^{\prime} \mathrm{S}\right.$, $149^{\circ} 48^{\prime} \mathrm{E}$ ) situated in the brigalow region of Central Queensland. The climate is tropical with rainfall throughout the year, but with most falling during the summer.

The experiment took place between the end of July and early November. There was no rainfall during the experimental period that the cattle were on the commercial property, but rain fell on 13 days when the cattle were in the feedlot. A summary of the weather conditions during the feedlotting period is given in Table 1.

\section{Animals}

One hundred Brahman steers were selected from 2 paddock groups (51 from one and 49 from the other) on the basis of number of permanent teeth (2-6 teeth) and a pre-determined range of fasted liveweights. The cattle were born on the property and had been mustered and handled through the yards once or twice each year from the time they were weaned and castrated at about 4-7 months of age.

Experimental procedures on the commercial property

On the first day (day -12) the steers were separately mustered, about $10 \mathrm{~km}$, from their paddocks to a set of yards for weighing, recording number of teeth and flight speeds. They were held as separate paddock groups overnight (without feed, but with ad libitum access to water) and weighed again the next morning (day-11) to obtain a fasted liveweight.
The animals were allocated to 5 replicate groups of 2 treatments matched as closely as possible for fasted liveweight (mean $446.5 \mathrm{~kg}$, range $399-500 \mathrm{~kg}$ ) and flight speed (mean $2.27 \mathrm{~m} / \mathrm{s}$, range $0.77-3.40 \mathrm{~m} / \mathrm{s}$ ). Flight speed was recorded using the method of Burrow et al. (1988), with the time taken for an animal to travel $1.6 \mathrm{~m}$ on release from the weighing crate being measured. This value was converted to $\mathrm{m} / \mathrm{s}$ for analysis.

Within each of the 10 groups, 4 steers were selected as focal animals for the recording of their behaviour and removal of blood samples during their time in the feedlot (data not presented in this paper). The focal animals were balanced, as much as possible, for fasted liveweight (day -11$)$ and flight speed (day -12$)$ across groups and treatments.

All selected steers were vaccinated against bovine ephemeral fever and common clostridial diseases and were ear-tagged for individual identification, and the focal animals had a blood sample taken by coccygeal venipuncture. The steers were divided into the 2 treatment groups and held in yards overnight with ad libitum access to peanut and lucerne hays and water.

The following day (day -10), at about 1600 hours, 1 group of steers (naïve treatment) was walked to a holding paddock ( 395 ha) containing pasture of low quality, and the other group (pre-exposed treatment) remained in the yards. The yarded animals had access to 2 yards: one that measured about 15 by $50 \mathrm{~m}$, where the animals had feed placed; and the other that measured about 12 by $28 \mathrm{~m}$, where there was ad libitum access to water. Lucerne hay was available from 3 self-feeders positioned in-line in the centre of the yard. Two troughs (each about $3 \mathrm{~m}$ long) were placed on 1 side of the yard and these contained a concentrated grain supplement containing urea, monensin and virginiamycin (Coleman Stock Feeds ' $3 / 4+$ P'; 13.3\% protein, $1.25 \%$ urea, $24.94 \mathrm{mg} / \mathrm{kg}$ monensin; $24.94 \mathrm{mg} / \mathrm{kg}$ virginiamycin).

The naïve treatment cattle stayed in the holding paddock for 9 days, during which time they had minimal exposure to people and vehicles, and were not provided with feed additional to the pasture. At the end of this period (day -2 ), the cattle were mustered and weighed. They were then kept in a yard for the remainder of the day (from 1100 hours) and overnight without feed and water. On the morning of day -1 (0630 hours) they were loaded onto a truck for transportation to Brigalow Research Station.

The pre-exposed cattle remained in the yards for 9 days. Each morning (at about 0730 hours) a vehicle loaded with feed entered the feeding yard. Bales of lucerne hay were placed in the 3 self-feeders and a $40 \mathrm{~kg}$ bag of concentrated grain supplement was divided between the 2 troughs. Having ensured that all the cattle were in the feeding yard, the gate to the water yard was closed and then, for about $1 \mathrm{~h}$, a person sat with, and walked slowly amongst the cattle. The cattle were then given access to both yards. Each afternoon (at about 1500 hours) the cattle were again moved into and confined in the feeding yard, and the person spent another hour in the yard with the cattle. On this occasion, the response of each animal to the approach of a human was scored (see below). At the end of this time, a vehicle was driven into the yard, the cattle were given more hay, and the gate to the water yard was opened. During their time in the yards the cattle consumed $570 \mathrm{~kg}$ of hay and $400 \mathrm{~kg}$ of concentrated grain supplement. The hay and supplement were always fully consumed. Feeding of hay was restricted because drought

Table 1. Temperatures, relative humidity and rainfall during feedlotting

\begin{tabular}{lrrrrc}
\hline & 29-31 July & Aug. & Sept. & Oct. & 1-7 Nov. \\
\hline Av. max. temp. $\left({ }^{\circ} \mathrm{C}\right)$ & 23.1 & 24.1 & 27.6 & 29.0 & 34.0 \\
Av. min temp. $\left({ }^{\circ} \mathrm{C}\right)$ & 3.7 & 8.5 & 10.8 & 15.3 & 18.8 \\
Av. rel. humid. $(\%)$ & 52.7 & 59.0 & 52.2 & 47.0 & 64.1 \\
Rainfall (mm) & 0.0 & 12.8 & 15.7 & 115.2 & 10.4 \\
\hline
\end{tabular}


conditions on the property meant that there was a demand elsewhere for the available hay, and as a consequence, the pre-exposed cattle were under-fed. The daily interactions and observations of the steers allowed us to ensure that the health and welfare of the animals were not compromised by the food restriction. As with the naïve group, these steers were kept off feed and water during day -2 and overnight before being loaded for transportation on the morning of day -1 .

Scoring response to human. The experimenter walked slowly towards the group of cattle, with the response of individual animals being scored on the following scale: (i) animal extremely wary and alert, backed off to 'hide' behind other animals as soon as experimenter entered the yard, and galloped away when experimenter was more than $10 \mathrm{~m}$ away; (ii) animal very wary and alert and backed off to 'hide' behind other animals, or galloped away when experimenter was about 8-10 m away; (iii) animal alert, initially stood its ground and then moved off at a trot when experimenter was $6-8 \mathrm{~m}$ away; (iv) animal relaxed, initially stood its ground and then moving off at a fast walk when experimenter was 3-5 m away; and (v) animal very relaxed, stood its ground and only moved off at a slow walk when experimenter was within $1-2 \mathrm{~m}$ of it.

This procedure was repeated several times during each session in order to score all animals. The test was conducted only on the feedlot pre-exposed treatment animals and was performed each day for the 9 days that they were held in the yards.

\section{Transportation to experimental feedlot}

The cattle were transported in 2 double-decked trailers hauled by a prime-mover. Each deck of each trailer contained 2 compartments and the cattle were divided into 4 groups for each treatment and assigned to compartments, balanced for deck and front/back of each trailer. The $950 \mathrm{~km}$ journey took $15 \mathrm{~h}$, which included driver breaks and checking the cattle, arriving at Brigalow Research Station at about 2230 hours. The cattle were unloaded, drafted into the 2 treatment groups and yarded separately with ad libitum access to good quality hay and water overnight.

\section{Procedures at the feedlot}

The next morning (day 0 at 0800 hours) the cattle were inducted to the feedlot. They were weighed, had their flight speeds recorded and had a growth promotant pellet ('revalor-S', Roussel Uclaf, Romainville, France; $140 \mathrm{mg}$ trenbolone acetate, $28 \mathrm{mg} 17 \beta$ oestradiol) inserted into their ear. A blood sample of about $8 \mathrm{~mL}$ was collected from the coccygeal vein of the focal animals. The cattle were maintained in the 2 treatment groups with ad libitum access to hay and water and left undisturbed until the following morning.

Starting at about 0800 hours on day 1 (feedlot entry), the cattle were drafted into their feedlot pen groups and put into their pens. Treatment groups were randomly assigned across the 10 feedlot pens: the naïve group were in pens $1,4,5,9$ and 10 and the pre-exposed in pens 2, 3, 6,7 and 8. Behavioural observations started immediately the cattle were placed in their pens and were conducted by 2 observers for 2 , 4-h periods starting at about 0700 hours and 1300 hours on days 1-14, 24-26, 38-40, 52-54, 73-75 and 94-96. Although the behavioural data are not reported in this paper, the presence of people is an important factor in this study.

Feedlot pens. The feedlot pens measured 5 by $30 \mathrm{~m}$, with a $4 \mathrm{~m}$ long feed-bunk positioned centrally at the eastern end of the pen. The pen surface contained an area of concrete extending $2 \mathrm{~m}$ from the feed-bunk and $1.2 \mathrm{~m}$ from the water trough while the remainder of the pen surface was an earth-manure 'pad'. The water trough, measuring 4 by $0.8 \mathrm{~m}$, was shared between adjacent pens and was located on the pen division at the western end of the pens. Shade cloth ( $75 \%$ exclusion), measuring $7.2 \mathrm{~m}$ wide (24\% of the pen area), ran across the middle of all pens (north-south) at a height of about $3.6 \mathrm{~m}$ from the ground. Pens were divided by either steel cables running between posts, or temporary fencing panels. Gates between pens at the western end allowed the entry and exit of cattle. To reduce the influence of cattle upon each other, hessian was used to cover pen dividers. However, the hessian had to be removed on day 29 because some cattle were eating it and we were concerned that this could result in gut impaction.

Feedlot management. The feedlot ration comprised $76 \%$ sorghum, $10 \%$ forage sorghum hay, $7.5 \%$ molasses, $2.5 \%$ Bentonite and $4 \%$ Farmstock '400 Plus' (Farmstock Pty Ltd, Biloela, Qld): a proprietary mixture containing $17.5 \%$ crude protein, $3 \%$ fat, $8 \%$ fibre, $12 \%$ calcium, $2 \%$ phosphorus, $4.5 \%$ sodium chloride, plus various trace elements, vitamins and other minerals. The grain was dry-rolled with the aim of achieving a rating of $90 \%$-cracked grain. The cattle were 'introduced' to this ration over a 21-day period, with increasing levels of grain and decreasing levels of fibre introduced at weekly intervals. Initially, the ration contained $16 \%$ grain, which increased to $76 \%$ at the end of the introductory period.

The cattle were fed twice daily with $30-40 \%$ of their expected intake delivered in the morning and the remainder in the afternoon. Feeding usually started at about 0800 hours and 1400 hours. The feed ration was mixed before each feeding session, with a sample of the mix taken at each session. These samples were bulked for each week of the experiment and a subsample of the weekly sample tested for dry matter content. All feed bunks were cleaned out weekly with a sample of the residue feed taken for dry matter analysis. All pen residues were individually weighed and pen group intakes calculated on a wet and dry feed basis for each week. Residues were also collected and weighed following rainfall. Water troughs were scrubbed and re-filled at least weekly.

The cattle were inspected for signs of injury, illness and lameness daily, both from the tractor-cab during feeding, and by a person walking through them. Any animal that was lying down was encouraged to stand and move. When the cattle were brought into the yards for data collection, they were again observed and inspected for any indications of ill-health or injury.

\section{Procedures for data collection}

The cattle were removed from their pens, a pen at a time (always in the same order), to the yards where they had their liveweights (days 0 , $5,9,16,27,41,55,69,76,83,90,97$ and 101), body condition scores (days 0, 41, 55, 76, 97 and 101) and flight speeds (days 0, 5, 16, 27, 41, 55,76 and 101) recorded. Body condition was scored on a scale of $1-9$, where 1 is emaciated and 9 is over-fat (Holroyd 1985). The pen group was then moved through the yards a second time and confined in the race so that blood samples could be collected from the coccygeal vein of the focal animals (days 0, 9, 16, 27, 55 and 76). The complete process took about $3.5 \mathrm{~h}$. A blood sample was collected from all animals on days $16,27,76$ and at exsanguination on day 102 .

\section{Pre-slaughter management}

The cattle had their last feed delivered on the morning of day 100 . On the morning of day 101, they were weighed, body condition scored and had their flight speeds recorded before being loaded onto 2 trucks. Each truck comprised a 4-compartment ( 2 upper and 2 lower deck) semi-trailer and a single-decked trailer with 2 compartments. The rear upper compartment on both semi-trailers was not used giving a total of 10 compartments each containing a pen group. Their location on the vehicle was balanced across the 2 treatments. Loading started at 0945 hours and took about $45 \mathrm{~min}$.

The distance to the abattoir was $120 \mathrm{~km}$ and the journey took $2 \mathrm{~h}$ 15 min, which included a stop to check the cattle. Unloading at the abattoir took about $35 \mathrm{~min}$. The cattle were yarded overnight in separate feedlot pen groups.

\section{Procedures at the abattoir}

The following morning (day 102) the cattle were moved into the abattoir from the lairage pens at about 0730 hours. These were the first 
animals to be slaughtered that day. Each group was moved into a washing pen where the cattle were sprayed with water under high pressure for 3-4 $\mathrm{min}$. They were then moved to a second pen where they were held until they were moved, in single file, to the stunning box.

The first animal entered the stunning box at 0740 hours; however, there was a breakdown and the animal was held there, with 4 others in the race leading to the stunning box, until 0800 hours when the slaughter process started. The order in which the feedlot pen groups were slaughtered was randomised, with treatment groups alternated, starting with a pen of the naïve treatment. The order that the animals were killed depended on the order that they entered the stunning box, and a record was kept of the order. An experimenter followed the progress of the cattle from the lairage pens until they were stunned and tipped out onto the processing floor to record how the animals were handled pre-slaughter. Stunning was by means of a captive bolt pistol, the animals were then hauled up onto the processing chain by a hind leg and the throat cut for exsanguination. A $10 \mathrm{~mL}$ blood sample was collected from each animal at this time. The last of the steers was slaughtered at 1020 hours (with breaks from 0830 to 0840 hours and 0945 to 1005 hours). It took about $45 \mathrm{~min}$ for carcasses to enter the chilling rooms from the time of slaughter.

Carcass data collected. The number of permanent incisors (dentition) was recorded and the carcasses were split into sides and weighed. From the carcass weight and the pre-trucking liveweight, the dressing percentage (carcass weight/liveweight $\times 100$ ) was calculated. Carcasses were scored for bruising (from 1 to 9 depending upon number, position and severity of the bruises), had butt profile (from A to $\mathrm{E}$, where $\mathrm{B}$ and $\mathrm{C}$ are the preferred shape for aesthetic reasons) recorded, P8 fat depth measured (mm) (AUS-MEAT 1998) and were graded according to market specifications.

A standard 'chiller assessment' (AUS-MEAT 1998) was obtained from the abattoir for all carcasses. This assessment takes place after overnight chilling of the sides and scores them for marbling (from 0 , no marbling, to 6 , heavy marbling), meat colour (from 1A, 1B, 1C to 7, very light red to very dark red) and fat colour (from 0 , white, to 9 , creamy yellow). Additionally, after overnight chilling (21-25 h post slaughter) carcass temperature and $\mathrm{pH}$ measures were made with a hand-held device in the M. longissimus dorsi at the 12-13th rib area. This process started at 0545 hours and finished at 0900 hours.

\section{Data analyses}

Two periods of liveweight changes within the feedlot were considered: day 5-27 and 27-97. Day 5 was chosen as the starting point because the cattle lost weight between day -2 and 0 , with a greater loss in the pre-exposed animals than the naïve, presumably as a result of gut-fill differences in the 2 groups; so if day 0 had been used, subsequent gain would have been exaggerated. Further, the final day of feeding was 100, but cattle had a final liveweight taken on day 101, and had lost some weight. Therefore, we decided that the weight taken on day 97 was more appropriate as a final liveweight for analyses than that of day 101. Day 27 marked the point of change of pattern of liveweight gain. Subsequent to this day gain was linear, but before the pattern was non-linear.

The effects of treatment and focal status at each time were tested by ANOVA, with pen variation used to test the treatment effect for variables recorded after feedlot entry. Weight block, defined at allocation (day -11), was included as a term in the analyses of liveweights, average daily gains and intakes. Where these analyses indicated significant treatment by focal status interactions, REML methods were used to estimate the corresponding means and standard error of differences (s.e.d.), accounting for the nonorthoganality between the interaction and weight block. Pre-treatment (day -12) flight speed was included as a covariate in the analyses of flight speed at later times. Day effects and their interactions were initially tested by ANOVA with day as a subplot factor and the Greenhouse-Geisser
(Greenhouse and Geisser 1959) adjustment to degrees of freedom to allow for changing variability with time and for correlation between times. For flight speed, REML methods were also used to model the variability and correlations and to test the day effects more precisely.

Initial analyses of feed conversion efficiency (FCE: feed intake/liveweight gain) showed some extreme values because of weight gains near zero. Inverse FCE (liveweight gain/feed intake) was, therefore, used for the analyses testing effects on FCE.

Correlations between attributes, for example average daily gain (ADG) and flight speed, were calculated ignoring treatment effects. The statistical package GenStat (GenStat 2000) was used for all analyses.

\section{Results}

\section{Liveweight}

Liveweights differed significantly between the treatment groups on day $-2(P<0.001)$, day $0(P<0.001)$ and day 5 $(P<0.05)$, with the pre-exposed steers weighing less than the naïve. Thereafter, there was no significant difference and group means were virtually identical from day 16 onwards (Fig. 1). It took the animals until day 41 in the feedlot to return to the liveweight they were when first mustered and weighed (day -12). The liveweight losses associated with transportation were regained between days 9-16 in the feedlot.

The focal animals were significantly lighter on average than the non-focal animals at day $-2[434.7 \mathrm{~kg}$ and $443.8 \mathrm{~kg}$, respectively; s.e.d. $=3.2(P<0.01)]$ and day $0[415.3 \mathrm{~kg}$ and $421.5 \mathrm{~kg}$, respectively; s.e.d. $=2.6(P<0.05)]$. The difference at day -2 reflected the better liveweight gains of the naïve non-focal animals (Fig. 1). There was also a small $(1.8 \mathrm{~kg})$ but statistically significant $(P<0.05)$ difference at allocation to the trial (day -11$)$ : the focal animals being lighter than the

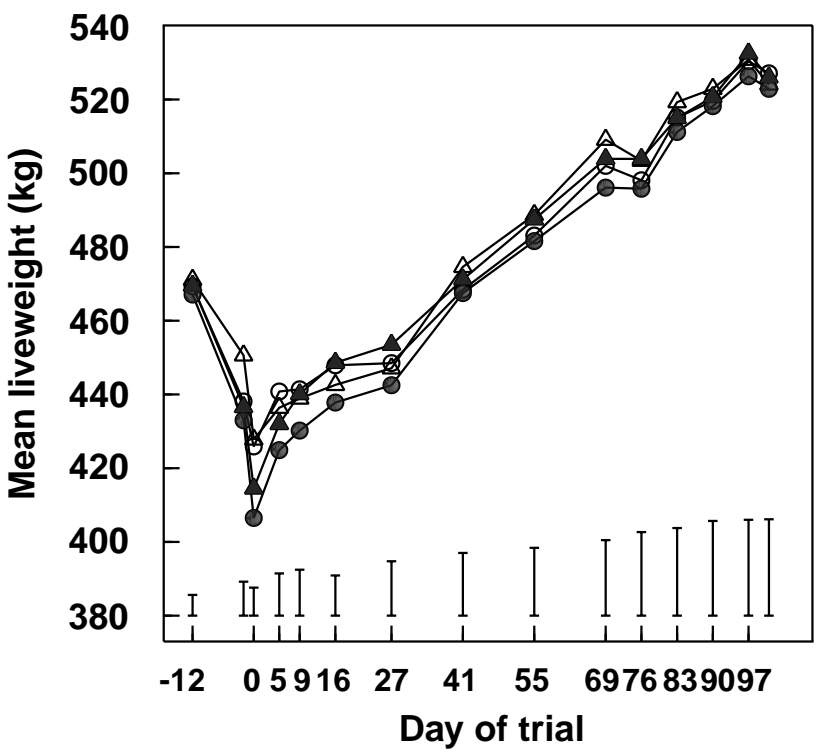

Figure 1. Mean liveweight $(\mathrm{kg})$ during feedlotting of steers according to treatment and focal status. Pre-exposed focal, $\bigcirc$ naïve focal, $\boldsymbol{\Delta}$ pre-exposed non-focal, $\triangle$ naïve non-focal. Bars indicate 1.s.d. $(P=0.05)$ for testing pre-exposed focal $v$. pre-exposed non-focal animals. 1.s.d. for other tests between group means are similar. 
Table 2. Pen intakes (kg fresh feed/steer.day) during periods (days, D) of feedlotting for pre-exposed and naïve treatments

\begin{tabular}{lllllccccc}
\hline Treatment & D 1-4 & D 5-8 & D 9-15 & D 16-26 & D 27-40 & D 41-54 & D 55-75 & D 76-96 & D 97-100 \\
\hline Pre-exposed & 6.50 & 8.88 & 12.88 & 13.73 & 13.09 & 14.38 & 14.37 & 14.00 & 13.90 \\
Naïve & 7.94 & 10.54 & 13.59 & 13.88 & 13.38 & 14.10 & 14.25 & 13.60 & 13.81 \\
s.e.d. & 0.276 & 0.342 & 0.273 & 0.577 & 0.938 & 0.910 & 0.710 & 0.977 & 1.148 \\
Signif. & $P<0.001$ & $P<0.001$ & $P<0.05$ & n.s. & n.s. & n.s. & n.s. & n.s. & n.s. \\
\hline
\end{tabular}

non-focal animals. There was no significant main effect of focal status from day 5 onwards. However, there was a significant $(P<0.05)$ interaction between treatment and focal status at day 16 , reflecting a slower liveweight recovery by the pre-exposed focal animals than the pre-exposed non-focal animals.

\section{Intakes}

Pen intakes $(\mathrm{kg} / \mathrm{steer}$.day) increased from day 1 to 9 with little variation after that time. The naïve treatment group had significantly higher intakes for the periods day $1-4,5-8$ and 9-15, but thereafter there was no difference between treatment groups (Table 2).

\section{Average daily gain}

As shown in Figure 2, mean ADG was negative between the first weighing (day -12) and transportation (day -2) with those in the pre-exposed treatment being significantly lower than those in the naïve treatment $[-3.36$ and -2.45 $\mathrm{kg} /$ steer.day, respectively; s.e.d. $=0.38(P<0.05)]$.

During the first phase of feedlotting (days 5-27), ADGs were significantly $(P<0.05)$ higher for the pre-exposed animals than the naïve animals $[0.88 \mathrm{~kg} /$ steer.day and

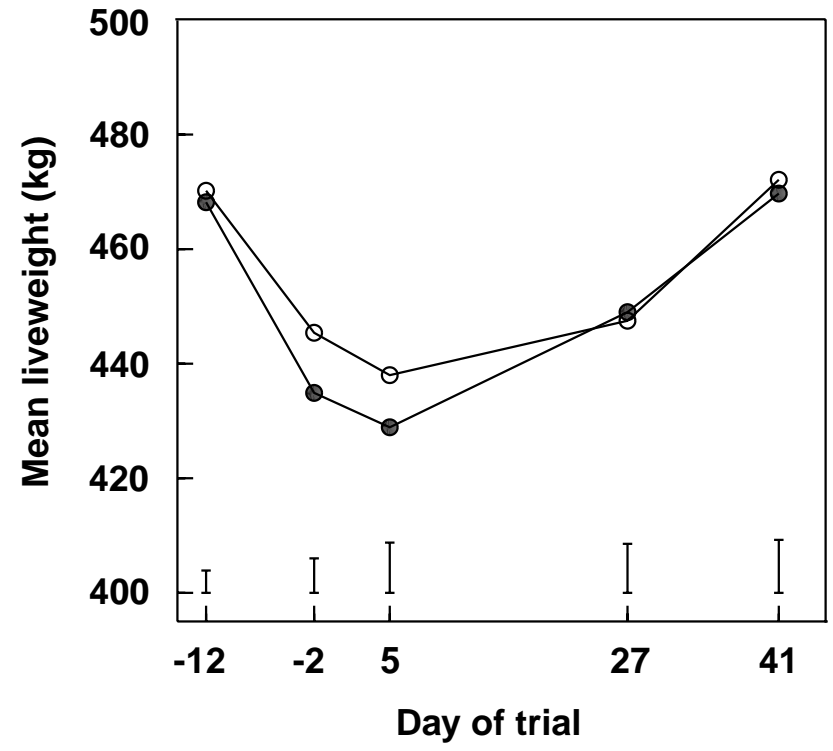

Figure 2. Average daily gains for steers in the naïve and pre-exposed treatments from the time of first weighing to the early phase of feedlotting. Pre-exposed, $\bigcirc$ naïve. Bars indicate 1.s.d. $(P=0.05)$ for testing pre-exposed $v$. naïve mean liveweights.
$0.45 \mathrm{~kg} /$ steer.day, respectively; s.e.d. $=0.18]$. Thereafter (days 27-97), there was no difference between the treatments $(1.10 \mathrm{~kg} /$ steer.day and $1.12 \mathrm{~kg} /$ steer.day for pre-exposed and naïve, respectively; s.e.d. $=0.11$ ).

There were no differences in ADG between focal and non-focal animals at any time during the trial.

Inverse feed conversion efficiency

Inverse FCE was examined for the periods day 0-5, 5-27 and 27-97. Table 3 shows that feed conversion was significantly better for the pre-exposed animals than the naïve animals during days $0-5(P<0.01)$ and 5-27 $(P<0.05)$. Thereafter, there was no significant difference.

\section{Body condition scores}

Body condition scores increased during the trial (Fig. 3), but treatment had no effect on mean condition score. Only on day 97 was there a significant $(P<0.05)$ difference between treatment groups, with the pre-exposed animals having a higher score than the naïve group [6.92 and 6.76, respectively; s.e.d. $=0.069$ ].

At induction, there was a significant treatment $\times$ focal interaction $(P<0.05)$ with the pre-exposed focal animals having a lower score than the others [naïve focal, 5.68; naïve non-focal, 5.50; pre-exposed focal, 5.32; and pre-exposed non-focal, 5.60; s.e.d. $=0.13-0.16]$. However, this pattern was not maintained with no subsequent significant interactions, and the pre-exposed focal animals having the highest mean condition score at the next recording date (day 41) (Fig. 3).

\section{Carcass traits}

Treatment had no effect on any of the carcass traits. None of the carcasses showed any bruising and all, except one, achieved the grade for the Japanese export market. The majority of the carcasses (83\%) had a butt profile score of C,

Table 3. Inverse FCE (kg gain/kg feed) (back transformed values in parentheses) during periods (days, $D$ ) of feedlotting for pre-exposed and naïve treatments

\begin{tabular}{llll}
\hline Treatment & \multicolumn{1}{c}{ D 0-5 } & \multicolumn{1}{c}{ D 5-27 } & \multicolumn{1}{c}{ D 27-97 } \\
\hline Pre-exposed & $0.55(1.83)$ & $0.072(13.83)$ & $0.083(12.11)$ \\
Naive & $0.28(3.62)$ & $0.032(31.65)$ & $0.085(11.74)$ \\
s.e.d. & 0.059 & 0.014 & 0.004 \\
Signif. & $P<0.01$ & $P<0.05$ & n.s. \\
\hline
\end{tabular}


with the remainder scoring $\mathrm{B}$. Three carcasses scored $1 \mathrm{C}$ for meat colour and the remainder scored 1B. Fat colour was scored as 0 for all carcasses except 3 , which scored 1 . Most carcasses scored 1 for marbling (91\%), 8\% scored 2 and 1 carcass scored 3 . Means of the other traits were dentition, 5.84 (s.e. 0.13); carcass weight, $284.21 \mathrm{~kg}$ (s.e. 2.55); dressing percentage, 54.19 (s.e. 0.19); P8 fat, $14.88 \mathrm{~mm}$ (s.e. 0.45 ); carcass temperature, $8.65^{\circ} \mathrm{C}$ (s.e. 0.082 ); and carcass $\mathrm{pH}, 5.63$ (s.e. 0.015).

\section{Flight speed}

Treatment did not affect flight speed or change in flight speed. Mean flight speed varied with day $(P<0.01$; Fig. 4$)$, with the average speed being less $(P<0.05)$ on days 76 and 101 than on days 16, 27, 41 and 55. Mean flight speed on day 76 was also less $(P<0.01)$ than on day -12 . The effect of focal status varied with time $(P<0.05)$ with mean flight speed for the focal animals being considerably lower than that of the non-focal animals on days 0,78 and 101, but higher on days 16 and 41 (Fig. 4). However, differences between the focal and non-focal animals at each day were not significant.

\section{Correlations}

The subjective temperament score made on the pre-exposed animals was significantly correlated with the flight speeds of that same group of animals on every occasion that flight speed was recorded. The $r$-values were $0.446,0.651,0.531,0.546,0.633,0.499,0.587,0.548$ for days $-12,0,5,16,27,41,55$ and 76 , respectively $(P<0.01)$ and 0.332 for day $101(P<0.05)$.

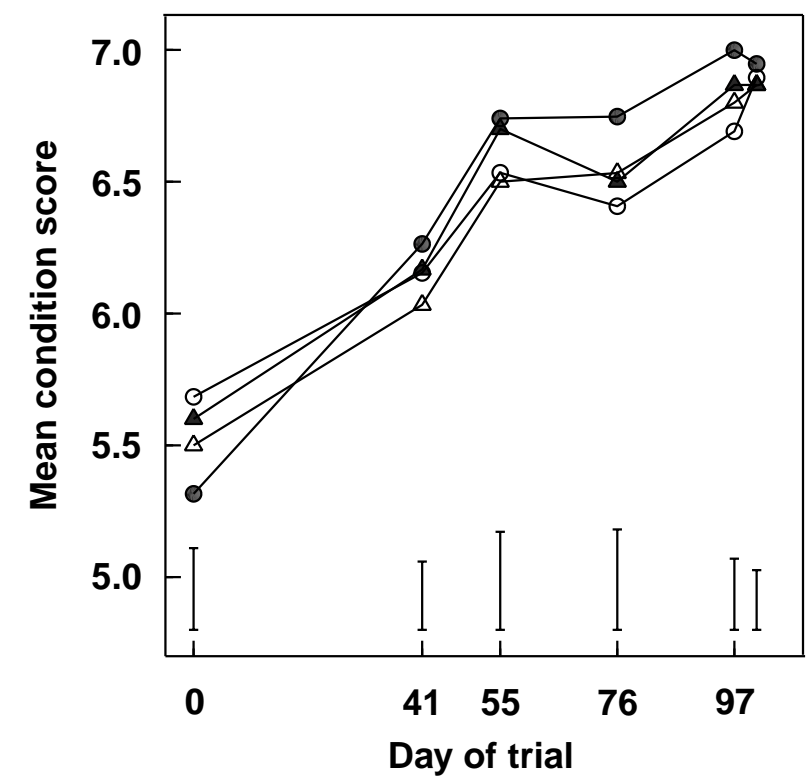

Figure 3. Mean body condition scores of steers during feedlotting according to treatment and focal status. Pre-exposed focal, $\bigcirc$ naïve focal, $\boldsymbol{\Delta}$ pre-exposed non-focal, $\triangle$ naïve non-focal. Bars indicate 1.s.d. $(P=0.05)$ for testing pre-exposed focal $v$. naïve focal animals. 1.s.d. for other tests between group means are similar.
Flight speeds were highly correlated $(P<0.01)$ between days; the $r$-values ranged between 0.480 (days 101 and -12 ) and 0.801 (days 41 and 76). Correlation values were lower between day 101 and all other days $(0.480-0.621)$, and day -12 and all other days $(0.480-0.655)$; the emerging pattern was for higher values the closer the days were to each other.

When all steers were considered, flight speed on day -12 was negatively correlated with ADG from days -12 to 97 $(r=-0.246 ; P<0.05)$, days -12 to $5(r=-0.275 ; P<0.01)$ and days -12 to $27(r=-0.244 ; P<0.05)$. Flight speed on day 0 was also negatively correlated with ADG from days -12 to 5 $(r=-0.228 ; P<0.05)$.

For the focal animals, flight speed on all days except 55 and 101 was negatively correlated with ADG from days -12 to 5 ( $r$-values were in the range -0.336 to $-0.455 ; P<0.05$ ). Also, flight speed on day -12 was negatively correlated with ADG from days -12 to $97(r=-0.470 ; P<0.01)$. Flight speeds on days $-12,0$ and 5 were negatively correlated with ADG from days -12 to $27(r=-0.399,-0.361$ and -0.320 , respectively; $P<0.05$ ).

When all steers were considered, there were significant positive correlations $(P<0.05)$ between dentition and flight speed measured on days $0(r=0.224), 5(r=0.239)$, $41(r=0.221)$ and $55(r=0.232)$. A similar trend was seen for the focal animals with significant correlations $(P<0.05)$ between dentition and flight speed measured on days 5 $(r=0.375), 16(r=0.356), 41 \quad(r=0.443 ; P<0.01), 55$ $(r=0.391), 76(r=0.357)$ and $101(r=0.413 ; P<0.01)$. For all steers, dressing percentage was also positively correlated with flight speed measured at every occasion, with a

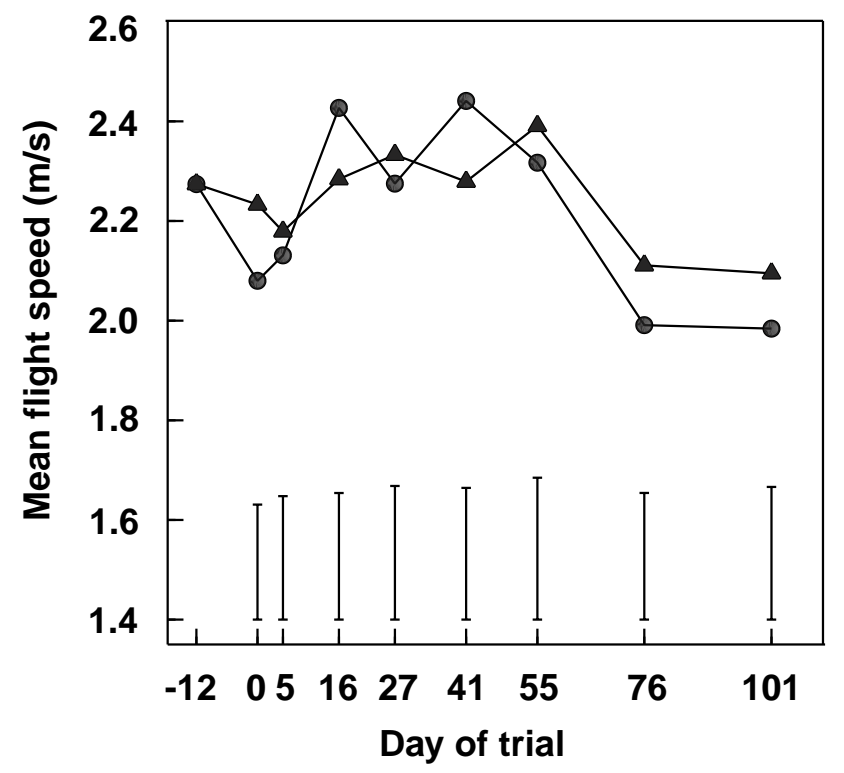

Figure 4. Mean flight speeds $(\mathrm{m} / \mathrm{s})$ of steers according to focal status. Focal, $\boldsymbol{\Delta}$ non-focal. Bars indicate 1.s.d. $(P=0.05)$ for testing focal $v$. non-focal animals. Average 1.s.d. for tests between day means (all steers) $=0.17$. 
correlation value of $r=0.325(P<0.01)$ between average flight speed of all days ( -12 to 101$)$ and dressing percentage. This pattern was less obvious when just the focal animals were considered, with significant correlations between dressing percentage and flight speed measured on day -12 $(r=0.385 ; P<0.05)$, day $0(r=0.422 ; P<0.01)$ and day 16 $(r=0.334 ; P<0.05)$.

Considering the carcasses of all steers and of the traits measured, P8 fat depth, carcass weight and dressing percentage were correlated $(P<0.01)$ with ADG from days -12 to 97 ( $r=0.407,0.749$ and -0.312 , respectively). These same traits were correlated $(P<0.01)$ with ADG from days 27 to 97 ( $r=0.381,0.699$ and -0.226 , respectively), and $\mathrm{P} 8$ fat depth and dressing percentage were correlated $(P<0.01)$ with ADG from days 5 to 97 ( $r=0.380$ and 0.739 , respectively). An almost identical pattern of results was obtained when only the focal animal carcasses were considered. When all carcasses were considered, carcass temperature was also correlated with ADG from days -12 to $97(r=0.215$; $P<0.05)$ and days -12 to $5(r=0.229 ; P<0.05)$. This pattern was not significant for the focal animal carcasses.

\section{Discussion}

The main aim of providing some of these steers with previous experience of aspects of a feedlot environment was an attempt to reduce fearfulness, resulting from novelty, so that the steers would rapidly become accustomed to their new environment. We had anticipated that experience of eating a feedlot concentrate from troughs would have resulted in the pre-exposed steers eating the feedlot ration with minimal delays, while fear would have reduced intakes by the naïve group. Certainly, there is evidence that experience of supplements increases subsequent acceptance and intake of the same and similar supplements in sheep (Lobato et al. 1980; Chapple and Lynch 1986) and cattle (Dixon et al. 2001). Also, work conducted in Texas on newly-inducted feedlot cattle showed that intakes were greater in cattle that had experienced 'backgrounding', which included experience of eating from feedbunks, compared with non-backgrounded cattle (Hutcheson and Cole 1986). However, the results were contrary to our expectations with the intakes of the naïve animals being significantly greater than those of the pre-exposed animals during the early part of feedlotting (Table 2). The reduced intake by the pre-exposed cattle during the initial part of feedlotting may have been connected with their restricted feed intake in the yards. Hutcheson and Cole (1986) stated that restricted feeding of feeder calves (those entering feedlots) before transportation results in a decreased feed intake post-transportation, although they gave no explanation of the mechanism of this effect (Cole and Hutcheson 1983).

We had also expected that experience of aspects of a feedlot environment would make the transition to a feedlot less of a stressor for the cattle, and that this would be reflected in productivity. Overall, pre-exposure had no beneficial effect on final liveweight (Fig. 1), or on body condition scores (Fig. 4) but it did affect weight gains during the first phase of the feedlotting period. The pre-exposed steers had daily weight gains double those of the naïve animals from days 5 to 27. Some of this effect would have been due to the previous greater liveweight loss of the pre-exposed steers, but it is notable that the pre-exposed steers did not eat as much as the naïve steers during the early part of feedlotting. Furthermore, the FCEs of the pre-exposed animals were about twice that of the naïve animals from days 0 to 27. Possibly the superior gains and FCEs were because the pre-exposed cattle had eaten small quantities (about $0.9 \mathrm{~kg} /$ steer.day) of the concentrated grain supplement on the property. There is ample evidence that changes in the proportions of roughage and concentrates in diets result in changes to the levels and types of rumen microbes (e.g. see Dehority and Orpin 1988). Therefore, it was likely that the digestive tracts of the pre-exposed animals were primed for concentrates and were more able to cope with the feedlot ration and make more efficient use of it initially compared with the naïve treatment animals.

We were particularly interested in the productivity of the focal animals because it has been suggested that cattle will not become accustomed to repeated procedures/human interactions if those procedures/interactions are unpleasant and/or painful (Grandin 1997). The focal animals were restrained and blood-sampled more frequently than the non-focal animals and we were concerned that their productivity would be affected because the restraint and blood sampling would act as stressors. In addition, these procedures may have caused the focal animals to become increasingly fearful of humans because of their aversive nature (Hemsworth and Coleman 1998). This fearfulness may have discouraged the animals from feeding during periods when people were recording behaviour and induced a stress response during these times and others when humans were in close proximity. Indeed, in subsequent studies we have observed that some cattle would not approach the feedbunk when people were present conducting behavioural observations.

The only evidence of the focal animals having their productivity compromised was that the pre-exposed focal animals had a slower liveweight recovery to day 16 than the pre-exposed non-focal animals. In this time period, the focal animals had been restrained for blood sampling on 3 occasions (days $-11,0$ and 9) while this procedure had not been conducted on the non-focal animals. However, if there was an effect of restraint and blood sampling then the same pattern should have been seen in the naïve group, but it was not. Furthermore, the ADGs and FCEs of the focal and non-focal animals did not differ. This is not to say that the focal animals became accustomed to the restraint and blood 
sampling, but rather that any stress responses resulting from the procedures were not manifested in the animals' productivity.

There is a large body of literature illustrating that handling and transportation of cattle are significant stressors (e.g. Tarrant et al. 1992; Grandin 1997; Palme et al. 2000; Dixit et al. 2001) and substantial liveweight losses occur (e.g. Warris 1990; Wythes 1994; Gallo et al. 2001). In the current experiment, cattle on both treatments showed a large loss of weight between when they were first mustered and feedlot induction (Fig. 1). Those on the pre-exposed treatment lost, on average, about $57 \mathrm{~kg}$ (about $12 \%$ of their original weight) whilst the weight loss for the naïve treatment group was less at $43 \mathrm{~kg}$ (about $9 \%$ ) on average. The losses associated with transportation per se (i.e. between day -2 to 0 ) were also substantial. The pre-exposed animals lost about $24 \mathrm{~kg}$ (about $5 \%$ of their day -2 weight) and had recovered this by day 9 in the feedlot. The naïve group lost about $18 \mathrm{~kg}$ (about 4\%) and did not regain this until day 16 in the feedlot. A proportion of these losses would have resulted from gut-fill and, during the transportation process, dehydration (Wythes 1994; Knowles 1999). These losses associated with transportation are in agreement with those reported by others, given the duration of the transportation (Tarrant 1990; Warris 1990; Wythes 1994; Knowles et al. 1999).

In the current study, it was not until day 41 in the feedlot that the animals of both treatment groups weighed the same as when they were first weighed on the property of origin, which is significantly longer than other reports in the literature. Knowles et al. (1999) found that cattle transported for up to $31 \mathrm{~h}$ (including a rest/drinking stop after $14 \mathrm{~h}$ ) returned to $1 \%$ below their pre-transportation weight at the end of $72 \mathrm{~h}$ on hay and water. In contrast, Wythes (1994) reported 10-21 days as the time taken to recover liveweight losses once animals have been returned to full feed, regardless of whether this is in a feedlot or on pasture. We suspect that this type of variation in liveweight recovery time is understandable given the probable differences in management practices, road quality, climatic conditions and total times off feed and water during transportation. Indeed, Wythes (1994) reported a limited number of studies and stated that further research into this area was required.

Our results also demonstrate that large liveweight losses by cattle (5\%) can occur even when they are not transported, as in the case of the naïve group on property between day -12 and day -2 . There is a rapid loss of liveweight associated with deprivation of feed and water, much of which is associated with gut-fill, which in adult cattle can account for $12-22 \%$ of liveweight (Wythes 1994). The liveweight loss experienced by the naïve group was, therefore, likely to have been due to a change in gut content, as a result of the animals having intermittent access to feed and water over a 2-day period before their return to the paddock. It was surprising, however, that the naïve group failed to show any liveweight gain during the 9 days that they were in the paddock. The property was experiencing drought conditions, but there was still ample pasture in the paddock, although the quality was likely to have been poor. The liveweight loss by the naïve steers during this 9-day period may also have arisen because they were placed in an unfamiliar paddock, rather than returned to their home paddock. There is anecdotal evidence that cattle placed in unfamiliar paddocks can spend some days 'fence-walking' with severe disruption to their normal grazing, ruminating and resting patterns. Such a dramatic change in the behavioural repertoire would, undoubtedly, have consequences for liveweight. The liveweight losses on property were significantly greater for the pre-exposed animals than the naïve steers (about 3.3 and $2.5 \mathrm{~kg} /$ steer.day, respectively) because the pre-exposed animals were under-fed, with most of their energy coming from the low bulk supplementary feed.

We recorded flight speed as a measure of cattle temperament (Burrow 1997) and we have previously suggested that temperament is indicative of the fearfulness of the animal (Petherick et al. 2002). The flight speed test (Burrow et al. 1988) involves many aspects that could be frightening to an animal, such as close proximity to humans, close confinement and social isolation. A problem with the test (as with many other so-called temperament tests) is that we are unsure whether or not we are measuring fearfulness of a particular aspect of the test, such as humans, close confinement or social isolation. In this trial, we found a moderate correlation between a subjective scoring of fearfulness of humans and flight speed ( $r$-values ranging between 0.332 and 0.651 ). As the subjective test did not involve social isolation or close confinement our results suggest that the flight speed test measures, in some part, a fear of humans. This being so, we would have expected changes in flight speed as a result of both treatment and focal status. However, neither treatment nor focal status affected flight speed. Exposure to humans in a situation where it is associated with food is likely to be perceived as positive by cattle (Boivin et al. 1992; de Passille et al. 1996). Thus, flight speeds should have decreased in the pre-exposed steers compared with the naïve ones, because the pre-exposed cattle had exposure to humans in a situation that was positive. Flight speeds should have increased in the focal animals compared with the non-focal animals, as a result of the negative handling they received.

These findings suggest that the fearfulness of these steers, and perhaps that relating to humans in particular, was unchanged by what we perceived as positive and negative interactions with humans. Indeed, judging from their productivity, their fear of novelty was also unaffected by their experience. Our failure to influence fearfulness may have arisen for a few reasons. Flight speed may be insensitive to experiential influences. Indeed, previous work has 
demonstrated that flight speed is highly repeatable (Burrow 1997; Petherick et al. 2002) and a trait that is moderately heritable (Burrow and Corbet 2000), factors which have led us to suggest that this test is largely a measure of the innate (and therefore 'fixed') aspect of fearfulness (Petherick et al. 2002). Having said this, we have found in previous work with young cattle that flight speed did change in animals that were restrained for blood and faecal sampling (Petherick et al. 1998). Perhaps then, age is critical in whether or not fearfulness can be influenced by experience. Most studies that have attempted to influence fearfulness, particularly of humans, have used young animals (Grandin 1997; Hemsworth and Coleman 1998; Boivin et al. 1998; Lensink et al. 2000; Krohn et al. 2001) and it is accepted that fearfulness can be modified by an individual's early experience (Mason 2000). These steers were 2-3 years of age when we attempted to affect their fearfulness. Perhaps by this age the animals' fearfulness was relatively 'fixed' and inflexible. Indeed, Fordyce et al. (1988b) suggest that temperaments of cattle over 2 years of age may not improve with increasing age. Our inability to affect flight speed may also have been simply a result of a difference between human and cattle perceptions as to what constitutes an unpleasant or pleasant interaction. We perceived that restraint and blood sampling would be aversive, and exposure in the context of food would be a positive experience for the steers. The work of Boivin et al. (1998) indicated that contact with calves perceived by humans as positive (brushing) may not be perceived as positive by the calves. Further, Pajor et al. (2000) handling dairy cattle found that treatments that humans may perceive as being innocuous (e.g. shouting) may be perceived as aversive by the cows.

Given that neither treatment nor focal status significantly affected the overall productivity of the steers it was not surprising that there were generally no effects on carcass traits.

ADG was correlated with a number of carcass traits; greater ADGs were related to greater P8 fat depths, higher carcass weights, higher carcass temperatures and lower dressing percentages. This suggests that higher gains lead to heavier and fatter carcasses and Wythes and Ramsay (1981) state that a heavy fat covering slows the rate of carcass chilling. The negative correlation between ADG and dressing percentage indicates greater waste, possibly due to heavier gastro-intestinal tracts and contents, and/or more fat trimmed from the carcasses (Wythes and Ramsay 1981).

Our results on the relationship between flight speed and productivity support previous findings that poor temperament cattle perform less well than cattle with good temperaments (Fordyce et al. 1985, 1988a; Voisinet et al. 1997; Fell et al. 1999; Petherick et al. 2002). This relationship was more evident in the early part of the experiment than later indicating that poor temperament animals lost more weight on property and in transit, and were slower to gain in the feedlot than the animals with a better temperament. We have suggested elsewhere (Petherick et al. 2002) that cattle with poor temperaments are more fearful, and, as a result, are more susceptible to stress. The stress responses of such animals mean that they are less efficient in maintaining and gaining weight.

Weak to moderate relationships between flight speed and some carcass traits were found in this trial. In the case of dentition score, this correlation is unlikely to be biologically meaningful as most (65\%) animals were scored as 6-tooth, with $17 \%$ as 4 -tooth and $13 \%$ as 8 -tooth (and the remainder a mix of 2- and 7-tooth).

A moderate positive correlation was found between flight speed and dressing percentage. This is a difficult relationship to explain because carcass weight per se was not related to flight speed and, so, this suggests that there was less wastage from the carcasses of the steers with poorer temperament. This was not related to carcass damage, as no bruising was found. Wythes and Ramsay (1981) state that individual components of offal do not significantly influence dressing percentage, but that the level of fatness and gut fill do. As ADG was negatively correlated with dressing percentage, this suggests that the poor temperament steers had less fat than the good temperament animals because of their poorer ADGs.

Although flight speed was unaffected by treatment and focal status it did vary with day. The pattern was for a slight (non-significant) rise in the first half of feedlotting, followed by a decrease. We have seen this same pattern in other work (Petherick et al. 2002) and have suggested that the decline in flight speed towards the end of feedlotting may simply reflect the reduced agility of the steers, as a result of their heavy liveweights.

As stated above, other work has found that flight speed is highly repeatable (Burrow 1997; Petherick et al. 2002) and our findings in this study that flight speeds were moderately to highly correlated between days support these previous findings. Furthermore, our finding that the flight speed recorded on the first occasion we handled these animals (day -12) was a significant covariate for flight speed measured on subsequent occasions, demonstrates that this first flight speed measure was a predictor of all of the others. These results further support the concept that flight speed testing could be a valuable tool to predict the productivity of mature cattle, and that it may need to be conducted only a small number of times to be reliable.

Overall, it appears that providing cattle of this age with this type of experience before feedlot-finishing was of limited value. We did not calculate the costs of providing the steers with the experience of aspects of the feedlot, but given the provision of the concentrated grain supplement and hay, plus the labour involved in feeding the cattle and any time spent with them, costs would have been significant. In this instance we found only transitory benefits in productivity and no reduction in the fearfulness of the animals. 


\section{Acknowledgments}

This study would not have taken place if not for the generosity of the Mann family; we thank them for allowing us to use their cattle and facilities at Hillgrove Station, and for their help and hospitality. We thank the staff of Brigalow Research Station, particularly the manager, Allan Lloyd, and the feedlot supervisor, Mark Oram, for the management of the cattle and their assistance with data collection. Our thanks also to Ian Loxton (Department of Primary Industries, Rockhampton) for measuring the carcass $\mathrm{pH}$ and temperatures. We are grateful to the staff of Teys Bros., Biloela, particularly Mick Thornton, for allowing us access to the abattoir for data collection.

\section{Animal ethics}

The use of animals in this experiment was approved by an Animal Ethics Committee in accordance with the 'Australian Code of Practice for the Care and Use of Animals for Scientific Purposes, 6th edition'. Animal care and management complied with the 'Australian Model Code of Practice for the Welfare of Animals. Cattle.'

\section{References}

AUS-MEAT (1998) 'Information 1. Language, chiller assessment, labelling, register of cuts and items.' (AUS-MEAT Ltd: South Brisbane)

Boissy A (1995) Fear and fearfulness in animals. The Quarterly Review of Biology 70, 165-191.

Boivin X, Le Neindre P, Chupin JM (1992) Establishment of cattle-human relationships. Applied Animal Behaviour Science 32, $325-335$.

Boivin X, Garel JP, Durier C, Le Neindre P (1998) Is gentling by people rewarding for beef calves? Applied Animal Behaviour Science 61, $1-12$.

Burrow HM (1997) Measurements of temperament and their relationships with performance traits of beef cattle. Animal Breeding Abstracts 65, 477-495.

Burrow HM, Corbet NJ (2000) Genetic and environmental factors affecting temperament of zebu and zebu-derived beef cattle grazing at pasture in the tropics. Australian Journal of Agricultural Research 51, 155-162.

Burrow HM, Seifert GW, Corbet NJ (1988) A new technique for measuring temperament in cattle. Proceedings of the Australian Society of Animal Production 17, 154-157.

Chapple RS, Lynch JJ (1986) Behavioural factors modifying acceptance of supplementary foods by sheep. Research and Development in Agriculture 3, 113-120.

Cole NA, Hutcheson DP (1983) Prefast plane of nutrition and realimentation in steers. Journal of Animal Science 57 (Suppl 1), 388.

Dehority BA, Orpin CG (1988) Development of, and natural fluctuations in, rumen microbial populations. In 'The rumen microbial ecosystem'. (Ed. PN Hobson) pp. 151-183. (Elsevier Science Publishers Ltd: London)

Dixit VD, Marahrens M, Parvizi N (2001) Transport stress modulates adrenocorticotropin secretion from peripheral bovine lymphocytes. Journal of Animal Science 7, 729-734.

Dixon RM, Smith DR, Porch I, Petherick JC (2001) Effects of experience on voluntary intake of supplements by cattle. Australian Journal of Experimental Agriculture 41, 581-592.
Dunn SE, Godwin J, Hoare RJT, Walker SB, Coverdale OR, Gibson JA (1998) Diseases of feedlot cattle in eastern Australia. In 'Proceedings of the 20th world association for buiatrics congress'. July 1998, Sydney. (Ed. IW Caple) pp. 159-164. (Australian Association of Cattle Veterinarians: Indooropilly, Qld)

Fell LR, Colditz IG, Walker KH, Watson DL (1999) Associations between temperament, performance and immune function in cattle entering a commercial feedlot. Australian Journal of Experimental Agriculture 39, 795-802.

Fordyce G, Dodt RM, Wythes JR (1988a) Cattle temperaments in extensive beef herds in northern Queensland. 1. Factors affecting temperament. Australian Journal of Experimental Agriculture 28, 683-687.

Fordyce G, Goddard ME, Tyler R, Williams G, Toleman MA (1985) Temperament and bruising of Bos indicus cross cattle. Australian Journal of Experimental Agriculture 25, 283-288.

Fordyce G, Wythes JR, Shorthose WR, Underwood DW, Shepherd RK (1988b) Cattle temperaments in extensive beef herds in northern Queensland. 2. Effects of temperament on carcass and meat quality. Australian Journal of Experimental Agriculture 28, 689-693.

Gallo C, Espinoza MA, Gasic J (2001) Effects of 36 hours road transport with or without a resting period on live weight and some meat quality aspects in cattle. Archivos de Medicina Veterinaria 33, 43-53.

GenStat (2000) 'Genstat for Windows, release 4.2 (5th edn).' (VSN International Ltd: Oxford, UK)

Gonyou HW (1993) Behavioural principles of animal handling and transport. In 'Livestock handling and transport'. (Ed. T Grandin) pp. 11-20. (CAB International: Wallingford, UK)

Grandin T (1997) Assessment of stress during handling and transport. Journal of Animal Science 75, 249-257.

Greenhouse SW, Geisser S (1959) On methods in the analysis of profile data. Psychometrika 24, 95-112.

Hemsworth PH, Coleman GJ (1998) Human-animal interaction and animal productivity and welfare. In 'Human-livestock interactions. The stockperson and the productivity and welfare of intensively farmed animals'. pp. 39-61. (CAB International: Wallingford, UK)

Holroyd RG (1985) Aspects of reproduction in Bos indicus genotypes. PhD Thesis, James Cook University of North Queensland, Townsville, Qld.

Hutcheson DP, Cole A (1986) Management of transit-stress syndrome in cattle: nutritional and environmental effects. Journal of Animal Science 62, 555-560.

Knowles TG (1999) A review of the road transport of cattle. Veterinary Record 144, 197-201.

Knowles TG, Warriss PD, Brown SN, Edwards JE (1999) Effects on cattle of transportation by road for up to 31 hours. Veterinary Record 145, 575-582.

Krohn CC, Jago JG, Boivin X (2001) The effect of early handling on the socialisation of young calves to humans. Applied Animal Behaviour Science 74, 121-133.

Lensink BJ, Boivin X, Pradel P, Le Neindre P, Veissier I (2000) Reducing veal calvesí reactivity to people by providing additional human contact. Journal of Animal Science 78, 1213-1218.

Lobato JFP, Pearce GR, Tribe DE (1980) Measurement in the variability in the intake by sheep of oat grain, hay and molasses-urea blocks using chromic oxide as a marker. Australian Journal of Experimental Agriculture and Animal Husbandry 20, 413-416.

Mason WA (2000) Early developmental influences of experience on behaviour, temperament and stress. In 'The biology of stress. Basic principles and implications for animal welfare'. (Eds GP Moberg, JA Mench) pp. 269-290. (CABI Publishing: Wallingford, UK)

Pajor EA, Rushen J, de Passille AMB (2000) Aversion learning techniques to evaluate dairy cattle handling practices. Applied Animal Behaviour Science 69, 89-102. 
Palme R, Robia C, Baumgartner W, Mostl E (2000) Transport stress in cattle as reflected by an increase in faecal cortisol metabolite concentrations. Veterinary Record 146, 108-109.

de Passille AM, Rushen J, Ladewig J, Petherick C (1996) Dairy calves' discrimination of people based on previous handling. Journal of Animal Science 74, 969-974.

Petherick JC, Holroyd RG, Doogan VJ, Cooper NJ (1998) Observations on the influence of repeated sampling procedures on temperament changes of weaner cattle. Proceedings of the Australian Society of Animal Production 22, 294.

Petherick JC, Holroyd RG, Doogan VJ, Venus BK (2002) Productivity, carcass and meat quality of lot-fed Bos indicus cross steers grouped according to temperament. Australian Journal of Experimental Agriculture 42, 389-398.

Tarrant PV (1990) Transportation of cattle by road. Applied Animal Behaviour Science 28, 153-170.

Tarrant V, Grandin T (1993) Cattle transport. In 'Livestock handling and transport'. (Ed. T Grandin) pp. 109-126. (CAB International: Wallingford, UK)

Tarrant PV, Kenny FJ, Harrington D, Murphy M (1992). Long distance transportation of steers to slaughter: effect of stocking density on physiology, behaviour and carcass quality. Livestock Production Science 30, 223-238.
Voisinet BD, Grandin T, Tatum JD, O'Connor SF, Struthers JJ (1997) Feedlot cattle with clam temperaments have higher average daily gains than cattle with excitable temperaments. Journal of Animal Science 75, 892-896.

Warris PD (1990) The handling of cattle pre-slaughter and its effects on carcass meat quality. Applied Animal Behaviour Science 28, 171-186.

Weston EJ, Harbison J, Leslie JK, Roenthal KM, Mayer RJ (1981) 'Assessment of the agricultural and pastoral potential of Queensland.' Queensland Department of Primary Industries, Agriculture Branch Technical Report No. 27, Brisbane, Qld.

Wythes JR (1994) 'Handling and transport of beef cattle. A literature review.' Livestock and Meat Authority of Queensland, Brisbane, Qld.

Wythes JR, Ramsay WR (1981) 'Beef carcass composition and quality.' Queensland Department of Primary Industries, Information series QI83002, Brisbane, Qld.

Received 23 December 2002, accepted 29 April 2003 